\title{
EVALUATION OF PUNCHING SHEAR IN FLAT SLABS
}

\author{
Alkarani ${ }^{1}$, Ravindra. $\mathbf{R}^{2}$ \\ ${ }^{1}$ Mtech student, ${ }^{2}$ Assistant Professor, Department of Civil Engineering, R.V College of Engineering, Bangalore \\ alkakathare@gmail.com,ravimurd@gmail.com
}

\begin{abstract}
Flat-slab construction has been widely used in construction today because of many advantages that it offers. The basic philosophy in the design of flat slab is to consider only gravity forces; this method ignores the effect of punching shear due to unbalanced moments at the slab column junction which is critical. An attempt has been made to generate generalized design sheets which accounts both punching shear due to gravity loads and unbalanced moments for cases (a) interior column; (b) edge column (bending perpendicular to shorter edge); (c) edge column (bending parallel to shorter edge); (d) corner column. These design sheets are prepared as per codal provisions of IS 456-2000. These design sheets will be helpful in calculating the shear reinforcement to be provided at the critical section which is ignored in many design offices. Apart from its usefulness in evaluating punching shear and the necessary shear reinforcement, the design sheets developed will enable the designer to fix the depth of flat slab during the initial phase of the design.
\end{abstract}

Keywords: Flat slabs, punching shear, unbalanced moment.

\section{INTRODUCTION}

Reinforced concrete slabs supported on columns were initially developed in the United States of America and Europe in the beginning of the 20th century [1].Their designs typically included large mushroom-shaped column capitals to facilitate the local introduction of forces from the slab to the column. In the $1950 \mathrm{~s}$, flat slabs without capitals started to become prevalent. Because of their simplicity, both for construction and for use (simple formwork and reinforcement, flat soffit allowing an easy placement of equipment, and installation underneath the slab); they have become very common for medium height residential and office buildings as well as for parking garages. The design of flat slabs is mostly governed by serviceability conditions on the one side (with relatively large deflections in service) and by the ultimate limits state of punching shear (also called two-way shear) on the other side. These two criteria typically lead to the selection of the appropriate slab thickness.

Punching shear failure is caused by the vertical shear and unbalanced moment borne by the slab-column connection, which makes the flat-slab connections a weak link in the whole flat-slab structure, and then leading to serious damage or even collapse. Unbalanced moments commonly occur in buildings with flat slabs, caused by unequal spans or loading on either side of the column. Differences of temperature or differential creep between two adjacent floors results in differential displacements of the top and bottom of the columns, which induce moments in the slab-column connection, even if the columns, as is assumed for this study, do not participate in the horizontal load resisting system. In the presence of such moments, the phenomenon of punching becomes unsymmetrical, and the punching strength of the slab decreases. This phenomenon has been described by researchers [2].

\subsection{Punching Shear Due To Unbalanced Moment}

The analysis for punching shear in flat slabs is assumed that the shear force, $V_{u}$ was resisted by shearing stresses uniformly distributed around the perimeter $b_{O}$ of the critical section, a distance $d / 2$ from the face of the supporting column. If significant moments are to be transferred from the slab to the columns, as would result from unbalanced gravity loads on either side of a column or from horizontal loading due to wind or seismic effects, the shear stress on the critical section is no longer uniformly distributed.

The situation can be modeled as shown in Fig. 1. Here, Vu represents the total vertical reaction to be transferred to the column, and $M_{u}$ represents the unbalanced moment to be transferred. The vertical force $V_{u}$ causes shear stress distributed more or less uniformly around the perimeter of the critical section as assumed earlier, represented by the inner pair of vertical arrows, acting downward. The unbalanced moment $M_{u}$ causes additional loading on the joint, represented by the outer pair of vertical arrows, which is added to the shear stress caused by $V u$. 


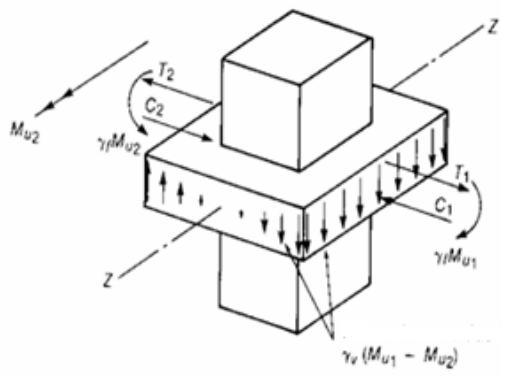

(a) Transter of unbalanced moments to column.

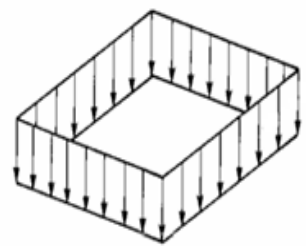

(b) Shear stresses due to $V_{0}$.

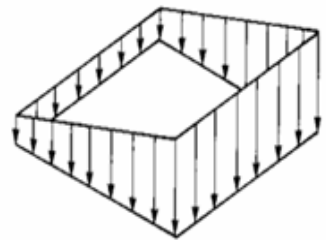

(d) Total shear stresses

Fig.1 Combined action of shear and shear due to moment transfer at interior column

According to IS 456-2000, Clause 31.3.3, the moment considered to be transferred by flexure is

$$
M_{u b}=\gamma M_{u}
$$

Where $\quad Y=\frac{1}{1+\frac{z}{a} \sqrt{a / b}}$

Where

$$
\begin{array}{llr}
a=c_{1}+d ; & b=c_{2}+d & \text { For Interior column } \\
a=c_{1}+\frac{d}{2} ; & b=c_{2}+d & \text { For Edge column } \\
a=c_{1}+\frac{d}{2} ; & b=C_{2}+\frac{d}{2} & \text { For Corner column }
\end{array}
$$

The fraction of moment transferred by the variation of shear stress about bending axis $\left(M_{w v}\right)$ is given in terms of the total moment $\left(M_{U}\right)$ transferred by eccentricity of shear about the centroid of the critical section for shear.

$$
M_{w v}=\gamma_{v} M_{u}
$$

Where $\gamma_{v}=(1-\gamma)$

According to the IS 456-2000, the shear stress may be taken linearly varying about the centroid of the section (Fig.1c). The shear stress at any point in the periphery arises from two effects, namely, that due to the shear force $V_{u}$ and that arising from transfer of unbalanced moment to column. Combining these two, the maximum shear stress $\tau$ is given by,

$$
\tau=\frac{V}{b_{0} d}+M_{w} \frac{c_{1}+d}{2 J}
$$

The value of $\mathbf{J}$ is computed from SP: 24-1983 Explanatory hand book to IS 456-2000.

For a structure to be safe, the punching shear stress should be less than the safe value. The ultimate safe value of the punching shear of concrete is given by the least value of the following two equations (IS 456 Clause 31.6.3)

$$
\begin{aligned}
& \tau_{p}=0.25 \sqrt{f_{c k}} \\
& \tau_{p p}^{\prime}=\left(0.5+\beta_{o}\right) \tau_{p}
\end{aligned}
$$

Eqn.(4) is the initial value suggested for a square column but research has shown that its magnitude is affected by the shape of the column so that it can be expressed for a rectangle by Eqn.(5), where $\beta_{g}=$ ratio of short side to long side of column capital. The code requires that the shear stresses should be investigated at successive sections away from the support, but does not indicate suitable intervals. It is suggested that these successive sections may be taken at intervals of $0.75 \mathrm{~d}$ (SP: 24-1983 Explanatory hand book to IS 456-2000). 
If the shear stress exceeds $1.5 \tau_{p}$, the flat slab shall be redesigned.

\section{ALGORITHM}

STEP 1:- Input- slab thickness (D), size of column $\left(C_{1} x C_{2}\right)$, factored design load $(\mathrm{V})$, unbalanced moment $\left(m_{x}, m_{y}\right)$, characteristic strength $\left(f_{c k}, f_{y}\right)$, section (s), length of opening (c), diameter of steel bars $\left(\mathrm{d}^{*}\right)$, diameter of stirrups(d')

STEP 2:- Compute effective depth

$$
\mathrm{d}=\mathrm{D} \text {-clear cover }-\mathrm{d} * / 2
$$

STEP 3:- Compute perimeter of shear zone

$$
a=c_{1}+d ; \quad b=c_{2}+d
$$

STEP 4:- Compute net length of shear zone

$$
c=a+b-c
$$

STEP 5:- Compute coefficients

$$
\gamma_{x}=\frac{1}{1+\frac{n}{3} \sqrt{\frac{a}{a}}} ; \quad \gamma_{y}=\frac{1}{1+\frac{z}{s} \sqrt{\frac{a}{a}}}
$$

STEP 6:- Compute bending moment and torsion moment

$$
\begin{array}{ll}
m_{b x}=\gamma_{x} m_{x} ; & m_{t x}=\left(1-\gamma_{x}\right) m_{x} \\
m_{b y}=\gamma_{y} m_{y} ; & m_{t y}=\left(1-\gamma_{y}\right) m_{y}
\end{array}
$$

STEP 7:- Compute centriodal distance

$$
\mathrm{X}=\mathrm{a} / 2 ; \quad \mathrm{y}=\mathrm{b} / 2
$$

STEP 8:- Compute moment of inertia

$$
j_{x x} i \quad j_{y y} \text { (As per the code IS 456-2000) }
$$

STEP 9:- Compute punching shear

$$
\begin{aligned}
& M_{x}=\frac{V}{b_{a} d}+\frac{m_{t w}}{j_{x y}} a \\
& M_{y}=\frac{V}{b_{v} d}+\frac{m_{b y}}{j_{y y}} b
\end{aligned}
$$

STEP 11:- Compute allowable shear stress

$$
\tau=\min \left\{\begin{array}{c}
(0.5+\beta) 0.25 \sqrt{f_{c k}} \\
0.25 \sqrt{f_{o}}
\end{array}\right\}
$$

STEP 12:- Check for safety, depth and shear links

If $\max \left(M_{x}, M_{y}\right)<\tau$, "safe", "unsafe"

If $\max \left(M_{x}, M_{y}\right)>1.5 * 0.25 \sqrt{f_{c k}}$ "revise the (go to step 1), "depth ok"

If $\max \left(M_{x}, M_{y}\right)>1.5 * 0.25 \sqrt{f_{z k}}$ and $\max$

$\left(M_{x}, M_{y}\right)>\tau$, "provide shear links", "no shear links is required"

STEP 13:- Terminate

STEP 13:- If shear link is to be provide, compute shear force at the distance $\mathrm{d} / 2$

$$
V_{u z}=\max \left(M_{w}, M_{y}\right) b_{p} d-0.5 b_{g} d t
$$

STEP 14:- Compute area of steel required

$$
A s v=\frac{v_{u z}}{0.87 f_{y}}
$$

STEP 15:- Compute area of steel required at each face of the column $\mathrm{A}_{\text {sve }}$

STEP 16:- Compute area of single stirrup

$$
a s t=\frac{\pi d^{2}}{4}
$$

STEP 17:- Compute spacing of bars

$$
S_{v}=\frac{a x t}{A x t} 2: a b
$$

STEP 18:- Check for minimum spacing as per the code IS 456

$$
S_{v}=2 * d \text {. }
$$

STEP 19:- Terminate

STEP 10:- Compute $\beta=$ ratio of shorter side to longer side of the column 


\subsection{Parametric Study of Punching Shear for Different}

\section{Aspect Ratio of Slab}

A parametric study is performed to evaluate the magnitude of punching shear due to unbalanced moments. The main parameter of the study is the aspect ratio of the slab and the corresponding variation of punching shear for the four types of column as described earlier. Table 1 summarizes the geometrical parameters used in the study and the results obtained. The loading on the slab and the unbalanced moments considered are the same for all the cases.

Table1. Variation of punching shear with respect to aspect ratio

\begin{tabular}{|c|c|c|c|c|c|}
\hline \multirow{2}{*}{$\begin{array}{c}\text { Panel dimensions } \\
\mathrm{L}_{2} / \mathrm{L}_{1}\end{array}$} & \multirow{2}{*}{ Aspect ratio } & \multicolumn{4}{|c|}{ Punching shear(N/mm $\left.{ }^{2}\right)$} \\
\cline { 3 - 6 } & & $\begin{array}{l}\text { Internal } \\
\text { column }\end{array}$ & $\begin{array}{l}\text { Corner } \\
\text { column }\end{array}$ & $\begin{array}{l}\text { Edge column (bending } \\
\text { parallel to shorter edge) }\end{array}$ & $\begin{array}{c}\text { Edge column (bending } \\
\text { perpendicular to shorter edge) }\end{array}$ \\
\hline $7 / 7$ & 1 & 2.79 & 18.21 & 4.29 & 9.70 \\
\hline $8 / 7$ & 1.14 & 3.42 & 22.4 & 5.39 & 11.09 \\
\hline $9 / 7$ & 1.29 & 4.09 & 26.98 & 6.61 & 12.49 \\
\hline $10 / 7$ & 1.43 & 4.82 & 31.96 & 7.95 & 13.88 \\
\hline $11 / 7$ & 1.57 & 5.60 & 37.34 & 9.41 & 15.27 \\
\hline $12 / 7$ & 1.71 & 6.44 & 43.11 & 10.99 & 16.76 \\
\hline $13 / 7$ & 1.86 & 7.34 & 49.28 & 12.70 & 19.54 \\
\hline $14 / 7$ & 2 & 8.28 & 55.84 & 14.52 & 22.53 \\
\hline
\end{tabular}

It can be concluded from Table 1 that as the aspect ratio increases, the punching shear in the slab also increases. Punching shear is found to be more critical at corner columns and least at interior columns.

\section{CONCLUSIONS}

Design sheets developed will help the designer to check for punching shear and calculate the shear reinforcement as per IS 456-2000 for different conditions of column locations. The program is validated by manual calculations and the results are found to be comparable. The design sheets developed will enable the designer to fix the depth of flat slab during the initial phase of the design in a simple manner.

\section{REFERENCES}

[1] Aurelio Muttoni; "Punching Shear Strength of Reinforced Concrete Slabs without Transverse Reinforcement", ACI Structural Journal, Title no. 105S42, pp. 440-450, July-August 2008.

[2] Gaston Kruger, Olivier Burdet, Renaud Favre; "Punching strength of R.C. Flat slabs with moment transfer", 2nd Intern. Ph.D. Symposium in Civil Engineering, Budapest 1998, pp. 1-8, Budapest, Hungary, 1998.

[3] Vikunj K.Tilva, B. A. Vyas, Parth Thaker; "Enhancing the punching shear resistance of flat plates using shear heads, shear stud rails and shear stirrups: a comparative study", Volume 04, No 06 SPL, pp. 596599, October 2011.
[4] IS 456:2000, "Indian standard code of practice for plain and reinforced concrete", Fourth Revision, Bureau of Indian Standards, New Delhi, July 2000. 